\title{
Dealing with Burnout
}

Last Updated: April 19, 2021

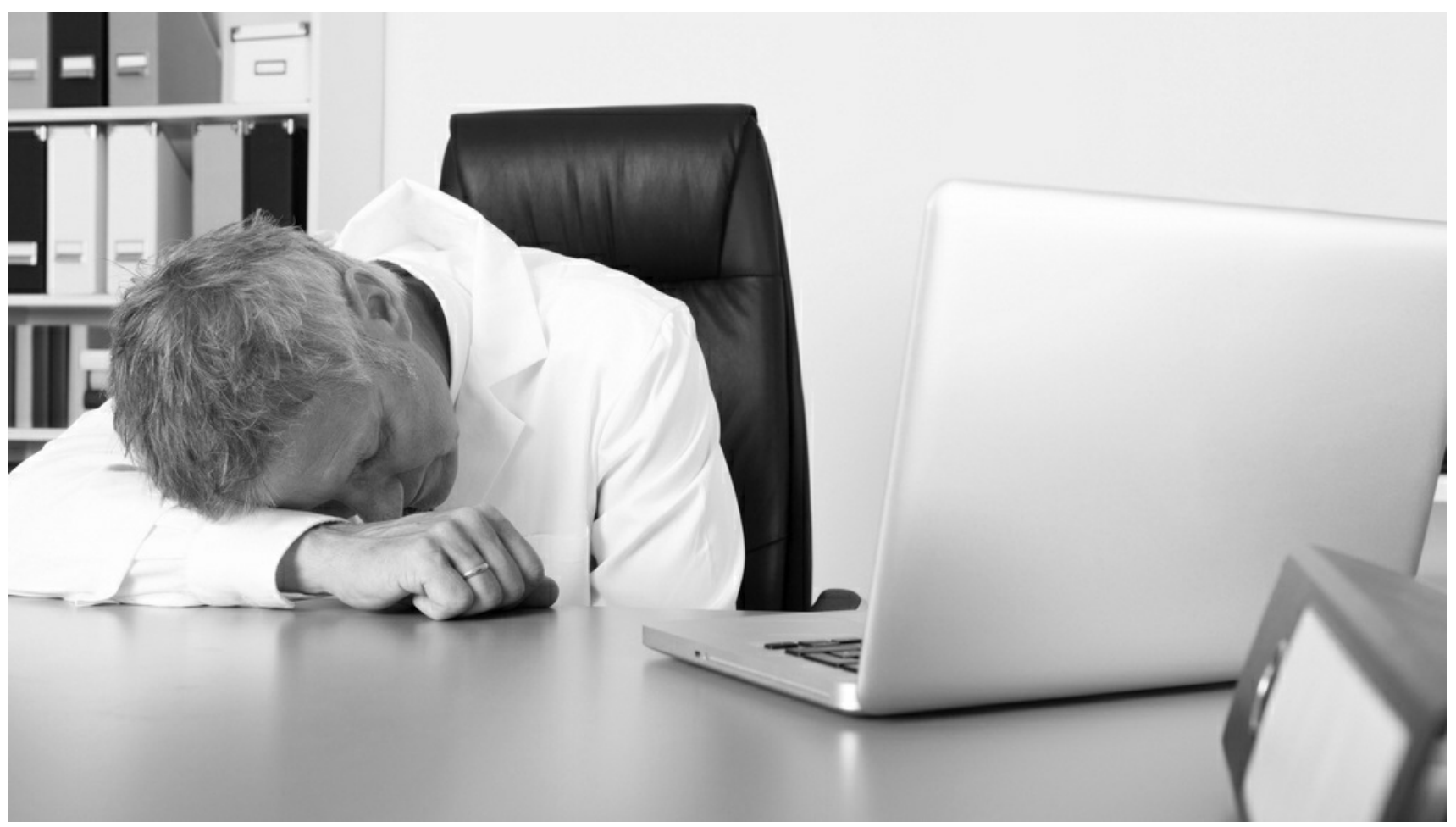

\section{INTRODUCTION}

Inadequate management of stress results in a state of mental, physical, and emotional exhaustion, and a perpetually drained mental, physical, and spiritual state eventually results in burnout. Given that these states are in constant flux, management of burnout requires a balance by

- decreasing energy disbursed by reducing stress and/or

- increasing energy reserves through alterations in lifestyle to enable more effective rejuvenation.

As was discussed in the Resilience in Neurosurgery chapter, particular scenarios can be considered risk factors for burnout:

- Working with distressed or difficult people

- Having strong motivation to work with people but feeling hindered 
by administrative tasks

- Having too much responsibility

- Being a perfectionist

- Having a mismatch between personal and work goals (often present in neurosurgical departments)

- Feeling guilty about personal needs

- Lacking the capacity to achieve a "good-enough" state of success

- Working with people who feel entitled to assistance with their problems

- Activities that provide novelty, variety, or diversion in daily life are frustrating

Not surprisingly, a state of burnout can have adverse effects on one's personal and professional lives. These effects include

- Cognitive dysfunction

- Blunted performance

- Physical breakdown

- Depersonalization

- Emotional exhaustion

- Dissemination of emotional distress

Given that according to the results of a 2014 survey, burnout rates within the US physician population approached $55 \%$, this deleterious state has an untold impact on the health care system. ${ }^{2}$ The focus of this chapter is the implementation of effective strategies for managing burnout and achieving a healthy work-life balance.

\section{STRATEGIES}

The initial step in appropriately managing and preventing burnout is recognition. One must recognize the current state of one's work-life 
balance before taking the next steps in this ongoing process/cycle. This dilemma is not one with a concrete answer and therefore cannot be solved; however, evolving management is the appropriate strategy.

The physician is in a unique work-life balance situation, such that his or her career choice provides a continuous conflict that pushes the balance in favor of work. This imbalance leaves little of what is left of the physician's time and energy for anything or anyone else. The use of boundaries and practice of healthy habits enable a tipping of the scales more in favor of life.

The following discussion presents methods for adding to the life side of the equation while still permitting the physician to fulfill his or her patient care obligations.

\section{Scheduling}

Structuring your life provides a means of maintaining a sense of balance and adherence to activities that provide purpose and pleasure in life. The first step is assessing the current contents of your calendar. This reflection provides a perspective on the important facets of your life, because the domineering priorities are inevitably reflected in those calendar contents. Does your calendar contain your spouse or family schedule, date nights, vacations, exercise, or personal time for hobbies?

If these activities are not in your calendar, they generally do not happen and therefore are not a priority to you. This is a critical realization to reach, because the importance of maintaining an organized calendar and pursuing a healthy work-life balance through scheduling requires you to take your calendar seriously. This calendar can be physical or electronic depending on your preference, but it requires frequent and ritualistic access.

The recommended steps to the scheduling approach depend on your preference of an electronic or physical calendar. Once you make this decision, provide yourself with the appropriate tools for maintaining your calendar and integrating it into your daily life. If you choose to use a 
physical calendar, you should consider making it visible and frequently encountered during your daily routine (for example, by placing it on your refrigerator). If you choose an electronic calendar, make sure it is synced with that of the appropriate member(s) of your family and that you have an appropriate device(s) from which to access and edit it.

The next step is populating the calendar. This should be a weekly process that becomes a ritual on a particular day of the week, such as a Sunday afternoon, during which time the coming week is discussed. During this process, the calendar should be reviewed by the family/household to ensure that each member's activities are represented. It is critical for you, the physician, to consider and include the activities or events outside of medicine in which you want to participate.

To ensure that this weekly tradition is maintained, be sure to include a scheduled time for the next session to review and add to the calendar.

For those of you who prefer a physical calendar, it is important to make this information readily available to you and your family during the week. Therefore, it is advisable to take a picture of the completed weekly calendar on your cell phone for quick reference when you are away from your home.

Making a schedule is somewhat easy; it is living by the schedule that becomes challenging, because as we all know, physicians' lives are seldom predictable. It is therefore crucial to familiarize yourself with saying "no." By having your calendar on your phone, you can reference it and be able to use the phrase "let me check my calendar" before accepting additional obligations.

If the request falls outside your scheduled time, then accepting the new responsibility is an option. However, if the new obligation conflicts with your schedule, you can say "I have a previous commitment and will not be able to help." Replying in this way might be challenging initially, because as physicians, we often embrace more professional responsibilities with open arms to maintain the perception that we are a team player. Keep in mind that to be the best and optimally functional member of the team, 
you have to care for yourself and your work-life balance as much as you care for your patients.

\section{Boundary Ritual}

Mentally taking off your white coat is more challenging than you might think and more often than not is achieved inadequately by most physicians. Bringing the stressors of work into your personal life prevents the rejuvenation normally imparted by enjoyable activities such as spending time with your significant other, partaking in hobbies, and vacationing.

Implementing the boundary ritual into your daily routine is simply a method of symbolically taking off your white coat and stepping into the role you maintain in your personal life (ie, as a parent, spouse, etc). This ritual should be something simple, such as a normal act of daily living such as showering, eating, listening to music, or changing your clothes. It should be short and something that is readily achievable even on busy days. The repetition of this activity and the adherence to mentally separating your personal life from your professional life after the performance of this ritual will prepare you better for mental rejuvenation at home.

\section{Maintaining Relationships}

The second major component of achieving a healthy work-life balance is maintaining your personal relationships, particularly your dating/marriage relationship. An unhealthy relationship that has significant magnitude within your life can cause immense depletion of emotional and physical resources, potentially to the point of prompting health problems.

Therefore, it is critical for you to intentionally plan for activities, such as "date night," at least twice per month. Date night might seem like a trivial and possibly exhausting activity after an already busy day, but strengthening one of the most important relationships in your life can have untold benefits by rejuvenating your mental status. If the stress of planning date night becomes too much, consider the importance of the priorities at hand. Maintenance and growth of a loving romantic 
relationship should be the utmost priority, and this is a reality that many of us do not take the time to reflect on.

To maintain a twice-monthly date-night minimum, it is important to plan or at least set the time for the next date during the current date night so that another date is always on the calendar. To encourage long-term success, consider planning out even farther, possibly a few months in advance, which will ensure that last-minute emergencies or unavoidable obligations do not disrupt this healthy trend overall.

For physicians who do not have a significant other, date night can look different but should still be pursued. It can be time with a friend or family member. If you are in a setting that does not permit social interaction, plan something spontaneous all by yourself. These activities can break the monotony of professional obligations and provide you a well-needed break.

\section{Setting Goals}

Goals have driven all of us in one way or another. Each physician has set goals along the path of training (for example, taking the Medical College Admissions Test, getting accepted into medical school, completing residency). These goals are often obvious, but we directed an immense amount of effort toward achieving them. Recording and referencing these goals is a healthy practice and should be incorporated into both your professional and personal realms.

Your professional goals are likely familiar to you and prompt many of your daily thoughts and activities. Setting personal goals is commonly neglected, unfortunately, but it is a critical additional step toward your achievement of a healthy work-life balance.

Personal goal-setting should include two types of goals. The first type includes the goals on your "bucket list," which require significant time and resources to achieve but provide an immense sense of accomplishment and purpose. The second type includes the activities on your weekly calendar. 
Bucket-list goals should be a facet of each of our lives and require significant consideration to pinpoint. Coming up with an appropriate list of these goals requires contemplation of questions such as "what would it feel like to die before achieving this goal?" If the thought of not achieving the goal prompts significant emotional unrest, then it should be on your bucket list.

Consistent pursuit of your bucket-list goals should become a part of your life. This quest should involve scheduling the activity on your calendar and investing in the activity, whether fiscally or through time spent planning. This process will ensure your continued pursuit of the goal with vigor. These steps could include blocking off time off, paying for plane tickets, and so forth.

Weekly goals are more motivational for your daily life. These activities should be the ones that provide you significant enjoyment and rejuvenation. After you identify these activities, the next step is to record them as weekly goals and begin incorporating them into your calendar schedule (as discussed above.) Examples of these goals might be hiking, meditating, or watching a movie. These activities should be feasibly incorporated into your weekly schedule to enrich you mentally.

\section{CONCLUSIONS}

The helpful techniques discussed here can be useful in breaking the cycle of burnout and bring satisfaction back into your life. Although everyone's life is different, physicians often possess similar unique challenges to their work-life balance. The adoption of these techniques is likely to enlighten your personal life and improve your ability to perform your professional duties through appropriate personal rejuvenation and sense of purpose.

Contributor: Benjamin K. Hendricks, MD

\section{DOI: https://doi.org/10.18791/nsatlas.v0.5.05}

\section{REFERENCES}

Drummond D. These 4 tools will enhance work-life balance. Retrieved 
from http://www.ismanet.org/ISMA/Resources/e-Reports/9-10-

$18 / 4$ tools will enhance work life balance.aspx. Accessed

September 7, 2018

Shanafelt TD, Hasan O, Dyrbye LN, et al. Changes in burnout and satisfaction with work-life balance in physicians and the general US working population between 2011 and 2014. Mayo Clin Proc 2015;90:1600-1613. doi.org/10.1016/j.mayocp.2015.08.023. 